\title{
Endoscopic Management of Pancreatic Fluid Collections: Guidelines of Society of Gastrointestinal Endoscopy of India and Indian EUS Club
}

\author{
Rahul Shah ${ }^{1}$ Jahangeer Basha ${ }^{2}$ Surinder Rana ${ }^{3}$ Soumya Jagannath ${ }^{4}$ Praveer Rai ${ }^{5, \odot}$ \\ Sudipta Dhar Chowdhury ${ }^{6, \odot}$ Zubin Dev Sharma ${ }^{7}$ Deepak Gunjan ${ }^{4, \odot ~ S a u r a b h ~ P a t l e ~}{ }^{7}$ \\ A Chalapathi Rao ${ }^{8, \odot ~}$ Prakash Zacharia $^{9}$ Rajesh Sanjeevi ${ }^{6} \quad$ Manoj Sahu ${ }^{10, \odot ~ M a t t h e w ~ P h i l i p ~}{ }^{9, \odot}$ \\ Pramod Garg ${ }^{4}$ Rajesh Puri ${ }^{7} \quad$ D Nageshwar Reddy ${ }^{2}$ Sundeep Lakhthakia ${ }^{2, \odot ~}$ Vinay Dhir $^{1}$
}

${ }^{1}$ Department of Gastroenterology, Institute of Digestive and Liver Care, SL Raheja Hospital, Mumbai, Maharashtra, India

${ }^{2}$ Department of Gastroenterology, Asian Institute of Gastroenterology, Hyderabad, Telangana, India

${ }^{3}$ Department of Gastroenterology, Postgraduate Institute of Medical Education and Research, Chandigarh, India

${ }^{4}$ Department of Gastroenterology, All India Institute of Medical Sciences, New Delhi, India

${ }^{5}$ Department of Gastroenterology, Sanjay Gandhi Postgraduate Institute, Lucknow, Uttar Pradesh, India

${ }^{6}$ Department of Gastroenterology, Christian Medical College,

Vellore, Tamil Nadu, India

${ }^{7}$ Department of Gastroenterology, Medanta The Medicity, Gurugram, Haryana, India

${ }^{8}$ Department of Gastroenterology, Iconkrishi Institute of Medical Sciences, Vishakhapatnam, Andhra Pradesh, India

${ }^{9}$ Department of Gastroenterology, Lisie Hospital, Kochi, Kerala, India

${ }^{10}$ Department of Gastroenterology, Institute of Medical Sciences and Sum Hospital, Bhubaneshwar, Odisha, India

J Digest Endosc 2021;12:3-10.

\section{Introduction}

The endoscopic management of pancreatic fluid collections (PFC) is in flux due to changes in how we classify them, as well as rapid advances in technology. The revised Atlanta classification of $\mathrm{PFC}^{1}$ clearly distinguished pseudocysts from walled-off necrosis (WON) and acute peri PFC from acute necrotic collections, based upon presence of necrosis, time since the onset of attack of pancreatitis and formation of a mature wall around the fluid collection. The literature prior to this had both, a mix of WON and pseudocyst, usually labeled as pseudocysts. ${ }^{1,2}$ The subsequent publications have clearly demonstrated that the management issues are different for pseudocyst and WON, although clarity still eludes several areas. Another major development has been the application of biflanged metal (BFMS) and lumen apposing

published online

March 11, 2021
DOI https://doi.org/

$10.1055 / \mathrm{s}-0041-1728956$ ISSN 0976-5042
Address for correspondence Vinay Dhir, MD,DNB,FASGE, Institute of Digestive and Liver Care, SL Raheja Hospital, Mahim, Mumbai, Maharashtra, 400016, India (e-mail: vinaydhir@gmail.com).

metal stents (LAMS) for PFC. Despite a lot of literature available for BFMS and LAMS, controversies still exist about their appropriate role. The Society of Gastrointestinal Endoscopy of India and Indian endoscopic ultrasound (EUS) club developed these guidelines to conduct an updated literature review, and provide recommendations based upon strength of available evidence. ${ }^{3}$

\section{Methods}

We invited 19 experts who had publications in peer-reviewed journals on PFCs to participate. Due to coronavirus disease-2019 pandemic, a physical participation and face-toface meeting were not possible and hence email and online meetings were conducted. An initial email was first sent to all the experts to formulate important questions regarding 
endoscopic management of PFCs. Experts were asked to focus on specific areas of current research on the definition, diagnosis, treatment, and technical aspects of PFC drainage. Sixty-one questions were received initially that were merged into eighteen questions after mutual discussions. The experts were then divided into teams of two, and each team was given two questions each for an exhaustive literature review, and subsequent formulation of a statement. Fourteen statements were thus compiled, and a summary of relevant literature was added. The level of evidence and strength of recommendation for each statement were added utilizing the evidence levelling system ${ }^{3}$ (-Table 1 ). The statements were circulated among the experts once more and any discordance was discussed and clarified.

\section{Statement 1}

Endoscopic Drainage Is Recommended for Symptomatic Pancreatic Fluid Collections (Walled-Off Necrosis or Pseudocyst) Located within Close Vicinity of Stomach or Duodenum

Level of Evidence: IIA, Grade of Recommendation: B

Endoscopic drainage should be considered for symptomatic PFC. The usual symptoms include abdominal pain, obstruction to the gastric outlet (vomiting), or bile duct (jaundice). Patients with suspected or proven infection should also be considered for endoscopic drainage. Infected WON can be

Table 1 Classification of evidence levels and recommendation grades

\begin{tabular}{|c|c|}
\hline $\begin{array}{l}\text { Level/Grade } \\
\text { Evidence level }\end{array}$ & Description \\
\hline I-A & Evidence from meta-analysis of RCTs \\
\hline I-B & Evidence from at least $1 \mathrm{RCT}$ \\
\hline II-A & $\begin{array}{l}\text { Evidence from at least } 1 \text { controlled study } \\
\text { without randomization }\end{array}$ \\
\hline II-B & $\begin{array}{l}\text { Evidence from at least } 1 \text { other type of quasi- } \\
\text { experimental study }\end{array}$ \\
\hline III & $\begin{array}{l}\text { Evidence from nonexperimental descriptive } \\
\text { studies, such as comparative studies, corre- } \\
\text { lation studies, and case-control studies }\end{array}$ \\
\hline IV & $\begin{array}{l}\text { Evidence from expert committee reports or } \\
\text { opinions or clinical experience of respected } \\
\text { authorities or both }\end{array}$ \\
\hline \multicolumn{2}{|l|}{$\begin{array}{l}\text { Recommendation } \\
\text { grade }\end{array}$} \\
\hline A & Directly based on category I evidence \\
\hline B & $\begin{array}{l}\text { Directly based on category II evidence or } \\
\text { extrapolated recommendation from cate- } \\
\text { gory I evidence }\end{array}$ \\
\hline C & $\begin{array}{l}\text { Directly based on category III evidence or } \\
\text { extrapolated recommendation from cate- } \\
\text { gory I or II evidence }\end{array}$ \\
\hline $\mathrm{D}$ & $\begin{array}{l}\text { Directly based on category IV evidence or } \\
\text { extrapolated recommendation from cate- } \\
\text { gory I, II, or III evidence }\end{array}$ \\
\hline
\end{tabular}

Abbreviation: RCT, randomized controlled trial.

Source: Adopted from Shekelle et al. ${ }^{3}$ suspected clinically by fever, leucocytosis, presence of gas in the collection on cross-sectional imaging, or can be proven by fluid aspiration and culture. ${ }^{4-6}$ Fluid collections are only amenable to endoscopic drainage if they are in close vicinity of stomach or duodenum. ${ }^{1,7-9}$

\section{Statement 2}

Endoscopic Transmural Drainage of Symptomatic PFC Should Be Performed When the Collections Have a Well-Formed Encapsulating Wall

Level of Evidence: III, Recommendation Grade: C Endoscopic drainage of PFC in absence of well-formed wall can result in pneumoperitoneum or pneumo-retroperitoneum and its consequent infective complications. Therefore, PFC are usually drained $>4$ weeks after the onset of acute pancreatitis when these collections have got encapsulated. It seems appropriate to delay the endoscopic drainage as long as possible because the solid debris in WON tends to liquefy over time thereby, making endoscopic transluminal drainage easier. ${ }^{1,10-16}$

\section{Statement 3}

Early (<4 Weeks of Onset of Acute Pancreatitis) Intervention as Compared with Delayed ( $>4$ Weeks after Onset of Acute Pancreatitis) Intervention Is Technically Feasible and Effective but May Be Associated with Higher Incidence of Adverse Events, Need for Surgery, and Longer Hospital Stay

Level of Evidence: III, Recommendation Grade: C

Few recently published studies have demonstrated the safety and efficacy of early transmural drainage during early phase ( $<4$ weeks) of acute necrotizing pancreatitis (ANP), thus expanding the role of endoscopic drainage in ANP. ${ }^{10-13}$ However, the data on efficacy and safety of early endoscopic drainage of PFC is limited and is from highly experienced tertiary care centers with extensive experience in pancreatic endotherapy. Therefore, we need to establish the safety and efficacy of early ( $<4$ weeks) endoscopic drainage of PFC before it can be routinely recommended. ${ }^{14-16}$

\section{Statement 4}

\section{EUS-Guided Access Is Preferred Over Conventional Endoscopic-Guided Access}

Level of Evidence: 1B, Grade of Recommendation: B EUS defines the PFC morphology and its contents including percentage of debris and also allows accurate assessment of wall maturity and interposing vessels. It helps to differentiate from other cystic lesions of the pancreas. It facilitates drainage of PFC that are not bulging into the lumen, a distinct advantage over conventional endoscopic drainage. Two randomized controlled trials (RCTs) showed the superior technical success of EUS-guided drainage over conventional endoscopic drainage for pancreatic pseudocysts with similar clinical success and complications. ${ }^{7-9,17-19}$ 


\section{Statement 5}

A Cross-Sectional Imaging Prior to Drainage Provides Useful Information

Level of Evidence: III, Strength of Recommendation:

Grade C

Preprocedure imaging assesses the maturity of cyst wall, proximity to gut lumen, size of the cyst, necrotic contents within the cyst, presence of pseudoaneurysms, and pancreatic ductal disruption. A contrast-enhanced computed tomography (CECT) or magnetic resonance imaging (MRI) examination is performed for assessing a PFC. T2-weighted MRI scan is better than CECT scan in assessing the necrotic contents of the cyst and the integrity of pancreatic duct. CECT scan is better in delineating venous thrombosis, collaterals, and pseudoaneurysms. ${ }^{20}$

\section{Statement 6}

Antibiotic Prophylaxis Is Recommended Prior to Drainage of Pancreatic Fluid Collection Level of Evidence: IV, Strength of Recommendation: D

- EUS-guided drainage of PFC potentially increases the risk of infection of the PFC due to instrumentation and possibility of inadequate drainage. Although multiple randomized controlled studies have tested the role of prophylactic antibiotics in prevention of infected pancreatic necrosis, there is paucity of data on the role of antibiotic prophylaxis prior to drainage of PFC. ${ }^{21,22}$ Current recommendations from expert consensus guidelines suggest the use of prophylactic intravenous antibiotics having broad spectrum coverage but the duration of antibiotic therapy is unclear.

\section{Statement 7}

A 19 Gauze Needle Is Used for Puncture of Cyst Cavity, Followed by Passage of $\mathbf{0 . 0 2 5}$ " or $\mathbf{0 . 0 3 5 " ~ G u i d e w i r e . ~}$ Track Dilation Is to Be Done with a Cystotome or a Balloon. Hot Stents May Not Need Any of These Steps Level of Evidence: IV, Strength of Recommendation: D The technique of PFC drainage involves cyst puncture, guidewire passage, tract dilation, and stent placement. There are no comparative studies regarding the needle used to puncture the cavity, although 19-gauge needle seems preferable as there is need to pass a stiff 0.025 " 0.035 " guidewire. Tract dilation is done with a coaxial cautery dilator ( $6 \mathrm{~F}$ cystotome) or a 6 or $8 \mathrm{~mm}$ balloon dilator, or a combination of the two. Balloon dilation up to $15 \mathrm{~mm}$ may be needed if multiple plastic stent (PS) placement followed by necrosectomy is planned. ${ }^{23}$ There is no evidence that cautery dilators increase the incidence of bleeding. Noncoaxial cautery instruments like precut-papillotome should be avoided. Hot stents are one step devices incorporating a cautery dilator and thus do not need prior track dilation.

\section{Statement 8}

Double Pigtail Plastic Stents Provide Adequate Drainage with Acceptable Safety Profile for Both Pseudocysts and WON

Level of Evidence: I B, Strength of Recommendation: B

Double pigtail PS are safe, economic, and effective. The treatment success rates of endoscopic drainage of PFC using PS have ranged from 69.7 to $96.6 \%{ }^{24}$ The caliber of double pig tail stent used ranges from 7 to $10 \mathrm{~F}$ and the median number of stents used varies from 1 to $4 .^{25-29}$

Till date no randomized studies have addressed the optimal number of PS that should be inserted for drainage of a PFC. In a retrospective study of 122 patients, no difference in the number of interventions required for treatment success was found with respect to the caliber of stents ( 7 Fr vs. 10 Fr: one intervention required in 87.7 vs. $90.5 \% ; p=0.76$ ) or the number of stents ( 1 vs. $>1$ stent: one intervention required in 88.9 vs. $88.6 \%, p=0.99) .{ }^{30}$ On multiple logistic regression analysis, the stent size and number were also not predictors of the number of interventions required for treatment success.

In another multicentric study from China, in all patients who achieved technical success, the clinical success for single-stent drainage versus multiple-stent drainage was $93.9(46 / 49)$ versus $97.4 \%(37 / 38)(p=0.799) .{ }^{25}$ There was no significant difference in secondary infection between the single-stent and multiple-stent placement groups (9/ 49 vs. 2/38, respectively; $p=0.134$ ).

In a RCT of plastic versus metal stent for drainage of walled-off pancreatic necrosis, the authors used the size of WON as the criterion for deciding the number of PS. They inserted at least one or more PS if size of WON was less than $10 \mathrm{~cm}$ and at least 2 or more if the WON size was more than $10 \mathrm{~cm}^{24}$

In a RCT comparing endoscopic versus laparoscopy drainage, a single 10F PS resulted in overall clinical success rate of $91 \%$ in the endoscopy group, although $50 \%$ of the patients required re-endoscopic lavage or necrosectomy for secondary infection. $6,17,31,32$

As a general recommendation, two stents (7-10 F) should be placed ( - Table 2 ).

\section{Statement 9}

\section{Lumen Apposing Metal Stents or Biflanged Metal} Stents Are Safe and Effective in Patients with WON Level of Evidence: IB, Strength of Recommendation: B WON with large amounts of necrotic debris may not be drained adequately by single or multiple PS due to their smaller diameter, thereby leading to possibility of infection. Large-bore metal stents provide the advantage of efficient drainage of thick WON contents and also enable subsequent necrosectomy if required, thus reducing the overall need for surgical intervention. Three designs of metal stents are available, BFMS (Nagi, Taewoong, South Korea), LAMS (Spaxus, Taewoong, South Korea, and Axios, Boston Scientific) and 
Table 2 Prospective studies of EUS-guided drainage of pseudocysts and walled-off necrosis utilizing LAMS, BFMS, or PS since 2012*

\begin{tabular}{|c|c|c|c|c|c|c|c|c|c|}
\hline Study & $\begin{array}{l}\text { Type of } \\
\text { study }\end{array}$ & $\begin{array}{l}\text { Type of } \\
\text { PFC }\end{array}$ & $\begin{array}{l}\text { Type of } \\
\text { stent }\end{array}$ & $\begin{array}{l}\text { Number of } \\
\text { patients } \\
(n)\end{array}$ & $\begin{array}{l}\text { Clinical } \\
\text { success } \\
(\%)\end{array}$ & $\begin{array}{l}\text { Technical } \\
\text { success } \\
(\%) \\
\end{array}$ & $\begin{array}{l}\text { Mortality } \\
\text { (\%) }\end{array}$ & $\begin{array}{l}\text { Adverse } \\
\text { events } \\
(\%)\end{array}$ & $\begin{array}{l}\text { Number } \\
\text { of DEN } \\
\text { (mean) }\end{array}$ \\
\hline Bang et $a^{33} 2019$ & $\mathrm{RCT}$ & WON & $\begin{array}{l}\text { LAMS } \\
\text { PS }\end{array}$ & $\begin{array}{l}31 \\
29 \\
\end{array}$ & $\begin{array}{l}93.5 \\
96.6 \\
\end{array}$ & $\begin{array}{l}100 \\
100 \\
\end{array}$ & 0 & $\begin{array}{l}41.9 \\
20.6 \\
\end{array}$ & $\begin{array}{l}2.8 \\
3.2 \\
\end{array}$ \\
\hline $\begin{array}{l}\text { van Brunschot et } \\
\text { al }{ }^{46} 2018\end{array}$ & $\mathrm{RCT}$ & WON & $\begin{array}{l}\text { PS } \\
\text { Surgery }\end{array}$ & $\begin{array}{l}51 \\
47 \\
\end{array}$ & 73 & 96 & 43 & 30 & 3 \\
\hline Garg et al' 2020 & $\mathrm{RCT}$ & $\begin{array}{l}\text { WON } 25 \\
\text { PP } 5\end{array}$ & $\begin{array}{l}\text { PS } \\
\text { Surgery }\end{array}$ & $\begin{array}{l}30 \\
30 \\
\end{array}$ & 90 & 96.6 & 0 & 10 & NA \\
\hline Dhir et al ${ }^{55} 2018$ & Prospective & WON & BFMS & 88 & 87 & 100 & 1.1 & 25 & 1.7 \\
\hline Dhir et a ${ }^{56} 2015$ & Prospective & PP & BFMS & 47 & 91.4 & 95.3 & 0 & 4.2 & 0 \\
\hline $\begin{array}{l}\text { Wang et al65 } \\
2016\end{array}$ & Prospective & $\begin{array}{l}\text { WON } 46 \\
\text { PP } 15\end{array}$ & LAMS & 61 & 93 & 98 & 0 & 33.3 & NA \\
\hline $\begin{array}{l}\text { Thompson et al }{ }^{32} \\
2016\end{array}$ & Prospective & WON & PS & 60 & 86.7 & 98.3 & 0 & 3.3 & 1.58 \\
\hline
\end{tabular}

Abbreviations: BFMS, biflanged metal stents; DEN, direct endoscopic necrosectomy; EUS, endoscopic ultrasound; LAMS, lumen apposing metal stents; “n," number; PP, pseudocysts; PS, plastic stents; RCT, randomized control trial; WON, walled-off necrosis.

* 2012 was chosen as cutoff as the revised Atlanta classification was published that year.

lumen apposing stents with cautery enhanced tip (Hot Spaxus, Taewoong, South Korea, and Hot Axios Boston Scientific, United States)

Choosing plastic or metal stent for EUS-guided drainage of WON is a subject of ongoing debate. A recent RCT concluded that apart from shorter procedure duration, there was no significant difference in treatment outcomes between LAMS and PS. ${ }^{33}$ A meta-analysis found no difference between LAMS and PS in the clinical success of WON drainage (88.5\% with LAMS vs. $88.1 \%$ with PS, $p=0.93$ ). However, the resolution of WON with LAMS was achieved with lesser mean number of procedures (mean: 1.5-2.8) as compared with PS (mean: 2.7-4.0). The rates for bleeding, sepsis, perforation, and stent-migration were similar between LAMS and PS, contrary to higher bleeding rates reported in LAMS group by another study. ${ }^{34-36}$

Another recent meta-analysis reported that the use of metal stents for drainage of PFC was associated with improved clinical success, fewer adverse events, and reduced bleeding compared with PS. ${ }^{29,37}$ Although LAMS have increased cost at index procedure, they provide easier access to perform direct endoscopic necrosectomy (DEN) and lead to reduced total number of procedures. Another three meta-analyses concluded that metal stents were superior to PS for endoscopic transmural drainage of PFC because they had a higher clinical success rate and lower rate of adverse events in particular infection and occlusion ${ }^{29,38,39}$ ( Table 2 ). In a prospective international multicenter study, use of LAMS facilitated DEN with low adverse events. ${ }^{40}$

\section{Statement 10}

The Addition of a Coaxial DPS Inside a LAMS/BFMS May Be Associated with a Lower Adverse Events, Need for Necrosectomy, and Lower Rates of Stent Migration Level of Evidence: IIA, Strength of Recommendation: C Adding a coaxial short double pigtail PS within the metal stent is primarily intended to prevent migration of BFMS. Other benefits have led to their use in LAMS as well.
A prospective study showed that there was a trend toward higher pseudocyst infection with LAMS alone, and placing a DPS across the LAMS minimized this risk. ${ }^{41}$ Another retrospective study reported lower adverse events with concurrent coaxial DPT insertion. In a retrospective study, a total of 41 patients were treated (21 LAMS alone; 20 LAMS plus DPS). The LAMS alone group had a significantly higher rate of adverse events than the LAMS plus DPS group (42.9 vs. $10.0 \% ; p=0.04$ ). Bleeding was the most frequent adverse event observed. ${ }^{42}$ On the contrary, another study reported no significant difference in fluid collection resolution or adverse events between patients drained by LAMSs alone versus those with LAMS plus DPS. ${ }^{43}$

\section{Statement 11}

Symptoms Suggestive of PFC Infection after Stent Placement for Walled-Off Pancreatic Necrosis (WON) Indicates the Need for Endoscopic Necrosectomy Level of Evidence: II A, Strength of Recommendation: Grade B

DEN has evolved as an important tool for the management of walled-off pancreatic necrosis, particularly after advent of LAMS with wider diameters. DEN can either be done in the same sitting as LAMS deployment (primary) or after a few days after index drainage (secondary). There is no clarity over which approach is better. A step-up approach was shown to reduce the need for necrosectomy. However, a large recent study showed that early necrosectomy may reduce the number of necrosectomy sessions. A variety of approaches are utilized for reducing the need for necrosectomy. These include utilizing a $20 \mathrm{~mm}$ LAMS, hydrogen peroxide irrigation, and continuous nasocystic saline irrigation. Better data are needed for each of these approaches. Endoscopic necrosectomy utilizing current devices is a slow and cumbersome technique and may require several sessions. The latter is considered in symptomatic patients with persistent or new onset symptoms such as fever or lack of significant resolution of PFC on imaging studies. ${ }^{44-52}$ 


\section{Statement 12}

a. For PFC drained with PS, long-term indwelling of transluminal stents should be kept in patients with proven disconnected pancreatic duct syndrome (DPDS).

\section{Level of Evidence: IB; Strength of Recommendation: Grade A}

b. For PFC drained with LAMS/BFMS, stent retrieval should be done within 4 to 6 weeks, with long-term indwelling PS to be placed in patients with DPDS.

\section{Level of Evidence: IIB; Strength of Recommendation: Grade B}

DPD is a potential risk factor for recurrent PFC, to prevent recurrence of PFC; one of the strategies proposed is to place transluminal PS at index drainage and leave them in situ indefinitely. If endoscopic drainage of PFC has been performed in a patient with a confirmed DPD diagnosed by magnetic resonance cholangiopancreatography (MRCP) and/ or endoscopic retrograde cholangiopancreatography (ERCP), long-term indwelling of transluminal PS is indicated. ${ }^{53,54}$ This approach has been based on a small RCT that included 28 patients with pseudocysts as predominant PFC having DPD in half of them. ${ }^{53}$ There was a significant reduction in recurrence in patients where the stent was left in situ compared with patients in whom the stent was removed after resolution (0 vs. 38\%). ${ }^{50}$ Since then, several retrospective studies have reported similar results of low recurrence of PFC having permanent indwelling PS along with low rate of spontaneous stent migration. ${ }^{54}$ Adverse events associated with long-term indwelling PS complications are few; however, data are inhomogeneous. In one series, two serious adverse events occurred due to small-bowel obstruction as a consequence of spontaneous stent migration. ${ }^{54}$ Infectious complications due to permanent indwelling stent have not been reported.

The strategy of permanent indwelling stents may be considered when the index drainage is done with PS. But in case where index drainage is done with metal stents, including LAMS, that cannot be kept for long-term due to adverse events like bleeding, an early removal has been recommended by 3 to 4 weeks. ${ }^{55,56}$ In such a scenario, replacement of metal stents by PS in residual PFC cavity has been proposed when there is associated DPD. However, it is often technically challenging to exchange a PS in a WON that is complete or has near completely resolved. In a recent prospective study, comparing plastic with metal stent, recurrent PFC was observed in 5 out of 24 patients (20\%) where PS could not be replaced with metal stents. None of the patient with PS replacement developed recurrent $\mathrm{PFC}^{57-59}$ ( - Table 3).

\section{Statement 13}

In Patients with Partial Disruption of the Main

Pancreatic Duct, Placement of a Transpapillary Stent, Bridging the Disruption May Be Considered. Stenting of the Pancreatic Duct Has No Role in Complete Disruption of Pancreatic Duct or DPDS

Level of Evidence: II; Strength of Recommendation:

Grade C

ERCP may be considered in patients with recurrence of PFC after removal of stents to evaluate for any pancreatic ductal disruption and to place transpapillary pancreatic ductal stenting if possible. In general, ERCP is not recommended if there is no recurrence or there is asymptomatic recurrence of small PFC. Pancreatic ductal disruptions following ANP can be partial or complete. Dynamic MRCP using secretin (s-MRCP) may suggest pancreatic ductal disruption. In patients with "partial ductal disruption" confirmed on ERP, a transpapillary pancreatic ductal stent bridging the leak should be done wherever it is possible. Whereas in "complete disruptions" that also known as DPD, bridging stent is not possible. Placing the stents in downstream pancreatic duct alone may not be effective. Another retrospective study observed that pancreatic ductal stent bridging the partial disruption leads to successful outcome. ${ }^{59,60}$ Similar observations were reported in another large retrospective study. ${ }^{61}$ The advantage of pancreatic ductal stenting was also reported in a retrospective study of patients with WON where they suggested combining transluminal drainage with transpapillary stenting to

Table 3 Recurrence and transpapillary stenting in patients with DPDS

\begin{tabular}{|l|l|l|l|l|l|l|l|l|}
\hline & Author & Type of study & $\begin{array}{l}\text { Number of } \\
\text { patients }(\boldsymbol{n})\end{array}$ & $\begin{array}{l}\text { DPDS } \\
(\%)\end{array}$ & $\begin{array}{l}\text { Permanent } \\
\text { indwelling } \\
\text { stents (\%) }\end{array}$ & $\begin{array}{l}\text { ERCP+ } \\
\text { plastic } \\
\text { stent (\%) }\end{array}$ & $\begin{array}{l}\text { Overall } \\
\text { recurrence } \\
(\%)\end{array}$ & $\begin{array}{l}\text { Recurrence in } \\
\text { DPDS }\end{array}$ \\
\hline 1 & $\begin{array}{l}\text { Arvanitakis et al } \\
2007\end{array}$ & RCT & 28 & 50 & 13 & 0 & 38.4 & 13.4 \\
\hline 3 & $\begin{array}{l}\text { Basha et al } \\
2021\end{array}$ & Retrospective & 274 & 74 & 0 & 12.5 & 13.2 & 17.4 \\
\hline 4 & $\begin{array}{l}\text { Dhir et al } \\
2018\end{array}$ & Prospective & 88 & 61 & 0 & 63.6 & 9.1 & 13.2 \\
\hline 5 & $\begin{array}{l}\text { Bang et al } \\
2020\end{array}$ & Prospective & 188 & 50 & 70 & 0 & 3.6 & 25 \\
\hline 6 & Wang et al ${ }^{65} 2020$ & Retrospective & 141 & 40 & 28 & 0 & 9 & 9 \\
\hline
\end{tabular}

Abbreviations: DPDS, disconnected pancreatic duct syndrome; ERCP, endoscopic retrograde cholangiopancreatography; $n$, number; RCT, randomized controlled trial. 
improve outcome. ${ }^{62}$ In a large study of 375 patients, there was no benefit of ERCP and transpapillary stenting in addition to transmural drainage in terms of long-term recurrence of PFC. ${ }^{63}$ A meta-analysis of nine studies also did not find any benefit of combined transmural and transpapillary drainage. ${ }^{64}$ In surgical series, transpapillary stenting has been reported after surgical cystogastrostomy with excellent long-term results. A RCT comparing endoscopic and laparoscopic cystogastrostomy without transpapillary stenting did not find any significant recurrence in either group. ${ }^{17}$ In another study, DPDS frequently occurs in patients with PFCs but does not negatively impact successful resolution. ${ }^{65}$ DPDS is associated with increased PFC recurrence after stent removal. ${ }^{67}$ ERCP carries a risk of post-ERCP pancreatitis and should be used judiciously. A distinction should be made between PFC following acute pancreatitis and PFC due to chronic pancreatitis. The risk of recurrence is higher in patients with PFC associated with chronic pancreatitis in whom a transpapillary stenting is often required.

\section{Conflict of Interest}

None declared.

\section{References}

1 Banks PA, Bollen TL, Dervenis C, et al. Acute Pancreatitis Classification Working Group. Classification of acute pancreatitis-2012: revision of the Atlanta classification and definitions by international consensus. Gut 2013;62(1):102-111

2 Dhir V, Maydeo A. EUS-guided pseudocyst drainage: has the metal proved its mettle.? Gastrointest Endosc 2015;82(5):828-830

3 Shekelle PG, Woolf SH, Eccles M, Grimshaw J. Developing clinical guidelines. West J Med 1999;170(6):348-351

4 Working Group IAP/APA Acute Pancreatitis Guidelines. IAP/ APA evidence-based guidelines for the management of acute pancreatitis. Pancreatology 2013;13,4(Suppl 2):e1-e15

5 Muthusamy VR, Chandrasekhara V, Acosta RD, et al. ASGE Standards of Practice Committee. The role of endoscopy in the diagnosis and treatment of inflammatory pancreatic fluid collections. Gastrointest Endosc 2016;83(3):481-488

6 Arvanitakis M, Dumonceau JM, Albert J, et al. Endoscopic management of acute necrotizing pancreatitis: European Society of Gastrointestinal Endoscopy (ESGE) evidence-based multidisciplinary guidelines. Endoscopy 2018;50(5):524-546

7 Varadarajulu S, Christein JD, Tamhane A, Drelichman ER, Wilcox CM. Prospective randomized trial comparing EUS and EGD for transmural drainage of pancreatic pseudocysts (with videos) Gastrointest Endosc 2008;68(6):1102-1111

8 Park DH, Lee SS, Moon SH, et al. Endoscopic ultrasound-guided versus conventional transmural drainage for pancreatic pseudocysts: a prospective randomized trial. Endoscopy 2009;41(10):842-848

9 Varadarajulu S, Wilcox CM, Tamhane A, Eloubeidi MA, Blakely J, Canon CL. Role of EUS in drainage of peripancreatic fluid collections not amenable for endoscopic transmural drainage. Gastrointest Endosc 2007;66(6):1107-1119

10 Trikudanathan G, Tawfik P, Amateau SK, et al. Early ( $<4$ Weeks) versus standard ( $\geq 4$ Weeks) endoscopically centered step-up interventions for necrotizing pancreatitis. Am J Gastroenterol 2018;113(10):1550-1558

11 Rana SS, Gupta R. Endoscopic transluminal drainage in the early phase of acute necrotising pancreatitis. Am J Gastroenterol 2019;114(4):688-689
12 Patel R, Gardner TB. Early versus late necrotic pancreatic fluid collection drainage: does timing make a difference.? Gastrointest Endosc 2020;91(6):1310-1311

13 Chantarojanasiri T, Yamamoto N, Nakai Y, et al. Comparison of early and delayed EUS-guided drainage of pancreatic fluid collection. Endosc Int Open 2018;6(12):E1398-E1405

14 Oblizajek N, Takahashi N, Agayeva S, et al. Outcomes of early endoscopic intervention for pancreatic necrotic collections: a matched case-control study. Gastrointest Endosc 2020; 91(6):1303-1309

15 Bang JY, Arnoletti JP, Holt BA, et al. An endoscopic transluminal approach, compared with minimally invasive surgery, reduces complications and costs for patients with necrotizing pancreatitis. Gastroenterology 2019;156(4):1027-1040.e3

16 Rana SS, Verma S, Kang M, Gorsi U, Sharma R, Gupta R. Comparison of endoscopic versus percutaneous drainage of symptomatic pancreatic necrosis in the early ( $<4$ weeks) phase of illness. Endosc Ultrasound 2020;9(6):402-409

17 Garg PK, Meena D, Babu D, et al. Endoscopic versus laparoscopic drainage of pseudocyst and walled-off necrosis following acute pancreatitis: a randomized trial. Surg Endosc 2020; 34(3):1157-1166

18 Teoh AYB, Dhir V, Jin ZD, Kida M, Seo DW, Ho KY. Systematic review comparing endoscopic, percutaneous and surgical pancreatic pseudocyst drainage. World J Gastrointest Endosc 2016;8(6):310-318

19 Teoh AYB, Ho LKY, Dhir VK, et al. A multi-institutional survey on the practice of endoscopic ultrasound (EUS) guided pseudocyst drainage in the Asian EUS group. Endosc Int Open 2015;3(2):E130-E133

20 Morgan DE, Baron TH, Smith JK, Robbin ML, Kenney PJ. Pancreatic fluid collections prior to intervention: evaluation with MR imaging compared with CT and US. Radiology 1997; 203(3):773-778

21 Isenmann R, Rünzi M, Kron M, et al. German Antibiotics in Severe Acute Pancreatitis Study Group. Prophylactic antibiotic treatment in patients with predicted severe acute pancreatitis: a placebo-controlled, double-blind trial. Gastroenterology 2004;126(4):997-1004

22 Pederzoli P, Bassi C, Vesentini S, Campedelli A. A randomized multicenter clinical trial of antibiotic prophylaxis of septic complications in acute necrotizing pancreatitis with imipenem. Surg Gynecol Obstet 1993;176(5):480-483

23 Varadarajulu S, Tamhane A, Blakely J. Graded dilation technique for EUS-guided drainage of peripancreatic fluid collections: an assessment of outcomes and complications and technical proficiency (with video) Gastrointest Endosc 2008;68(4):656-666

24 Gornals JB, Perez-Miranda M, Vazquez-Sequeiros E, et al. Spanish Working Group on Pancreatic Collection Therapy. Multicenter study of plastic vs. self-expanding metal stents in endoscopic ultrasound-guided drainage of walled-off pancreatic necrosis - PROMETHEUS: a randomized controlled trial protocol. Trials 2019;20(1):791

25 Lin H, Zhan XB, Sun SY, et al. Stent selection for endoscopic ultrasound-guided drainage of pancreatic fluid collections: a multicenter study in china. Gastroenterol Res Pract 2014;2014 :19356210.1155/2014/193562

26 Bang JY, Hawes R, Bartolucci A, Varadarajulu S. Efficacy of metal and plastic stents for transmural drainage of pancreatic fluid collections: a systematic review. Dig Endosc 2015;27(4):486-498

27 Ang TL, Kongkam P, Kwek ABE, Orkoonsawat P, Rerknimitr $\mathrm{R}$, Fock KM. A two-center comparative study of plastic and lumen-apposing large diameter self-expandable metallic stents in endoscopic ultrasound-guided drainage of pancreatic fluid collections. Endosc Ultrasound 2016;5(5):320-327 
28 Mukai S, Itoi T, Baron TH, et al. Endoscopic ultrasound-guided placement of plastic vs. biflanged metal stents for therapy of walled-off necrosis: a retrospective single-center series. Endoscopy 2015;47(1):47-55

29 Siddiqui AA, Kowalski TE, Loren DE, et al. Fully covered self-expanding metal stents versus lumen-apposing fully covered self-expanding metal stent versus plastic stents for endoscopic drainage of pancreatic walled-off necrosis: clinical outcomes and success. Gastrointest Endosc 2017;85(4):758-765

30 Bang JY, Wilcox CM, Trevino JM, et al. Relationship between stent characteristics and treatment outcomes in endoscopic transmural drainage of uncomplicated pancreatic pseudocysts. Surg Endosc 2014;28(10):2877-2883

31 Baron TH, DiMaio CJ, Wang AY, Morgan KA. American Gastroenterological Association Clinical Practice Update: management of pancreatic necrosis. Gastroenterology 2020; 158(1):67-75.e1

32 Thompson CC, Kumar N, Slattery J, et al. A standardized method for endoscopic necrosectomy improves complication and mortality rates. Pancreatology 2016;16(1):66-72

33 Bang JY, Navaneethan U, Hasan MK, Sutton B, Hawes R, Varadarajulu S. Non-superiority of lumen-apposing metal stents over plastic stents for drainage of walled-off necrosis in a randomised trial. Gut 2019;68(7):1200-1209

34 Mohan BP, Jayaraj M, Asokkumar R, et al. Lumen apposing metal stents in drainage of pancreatic walled-off necrosis, are they any better than plastic stents? A systematic review and meta-analysis of studies published since the revised Atlanta classification of pancreatic fluid collections. Endosc Ultrasound 2019;8(2):82-90

35 Tan S, Zhong C, Ren R, et al. Are Lumen-Apposing Metal Stents More Effective Than Plastic Stents for the Management of Pancreatic Fluid Collections: An Updated Systematic Review and Meta-analysis. Hindawi Gastroenterology Research and Practice Volume; 2020. London, UK

36 Saunders R, Ramesh J, Cicconi S, et al. A systematic review and meta-analysis of metal versus plastic stents for drainage of pancreatic fluid collections: metal stents are advantageous. Surg Endosc 2019;33(5):1412-1425

37 Navaneethan U, Njei B, Sanaka MR. Endoscopic transmural drainage of pancreatic pseudocysts: multiple plastic stents versus metal stents: a systematic review and meta-analysis. Gastrointest Endosc 2014;79:AB167-AB168

38 Yoon SB, Lee IS, Choi MG. Metal versus plastic stents for drainage of pancreatic fluid collection: a meta-analysis. United European Gastroenterol J 2018;6(5):729-738

39 Chen YI, Yang J, Friedland S, et al. Lumen apposing metal stents are superior to plastic stents in pancreatic walled-off necrosis: a large international multicenter study. Endosc Int Open 2019;7(3):E347-E354

40 Teoh AYB, Bapaye A, Lakhtakia S, et al. Prospective multicenter international study on the outcomes of a newly developed self-approximating lumen-apposing metallic stent for drainage of pancreatic fluid collections and endoscopic necrosectomy. Dig Endosc 2020;32(3):391-398

41 Aburajab M, Smith Z, Khan A, Dua K. Safety and efficacy of lumen-apposing metal stents with and without simultaneous double-pigtail plastic stents for draining pancreatic pseudocyst. Gastrointest Endosc 2018;87(5):1248-1255

42 Ali SE, Benrajab K, Mardini H, Su L, Gabr M, Frandah WM. Anchoring lumen-apposing metal stent with coaxial plastic stent for endoscopic ultrasound-guided drainage of pancreatic fluid collections: any benefit? Ann Gastroenterol 2019;32(6):620-625

43 Puga M, Consiglieri CF, Busquets J, et al. Safety of lumen-apposing stent with or without coaxial plastic stent for endoscopic ultrasound-guided drainage of pancreatic fluid collections: a retrospective study. Endoscopy 2018;50(10):1022-1026
44 Lakhtakia S, Basha J, Talukdar R, et al. Endoscopic "step-up approach" using a dedicated biflanged metal stent reduces the need for direct necrosectomy in walled-off necrosis (with videos). Gastrointest Endosc 2017;85(6):1243-1252

45 Rana SS, Sharma V, Sharma R, Gupta R, Bhasin DK. Endoscopic ultrasound guided transmural drainage of walled off pancreatic necrosis using a "step - up" approach: a single centre experience. Pancreatology 2017;17(2):203-208

46 van Brunschot S, van Grinsven J, van Santvoort HC, et al. Dutch Pancreatitis Study Group. Endoscopic or surgical step-up approach for infected necrotising pancreatitis: a multicentre randomised trial. Lancet 2018;391(10115):51-58

47 Elmunzer BJ. Endoscopic drainage of pancreatic fluid collections. Clin Gastroenterol Hepatol 2018;16(12):1851-1863.e3

48 van Brunschot S, Fockens P, Bakker OJ, et al. Endoscopic transluminal necrosectomy in necrotising pancreatitis: a systematic review. Surg Endosc 2014;28(5):1425-1438

49 Yan L, Dargan A, Nieto J, et al. Direct endoscopic necrosectomy at the time of transmural stent placement results in earlier resolution of complex walled-off pancreatic necrosis: results from a large multicenter United States trial. Endosc Ultrasound 2019;8(3):172-179

50 Puli SR, Graumlich JF, Pamulaparthy SR, Kalva N. Endoscopic transmural necrosectomy for walled-off pancreatic necrosis: a systematic review and meta-analysis. Can J Gastroenterol Hepatol 2014;28(1):50-53

51 Messallam AA, Adler DG, Shah RJ, et al. Direct endoscopic necrosectomy with and without hydrogen peroxide for walledoff pancreatic necrosis: a multicenter comparative study. Am J Gastroenterol 2020;10.14309/ajg.0000000000000987

52 Tamura T, Itonaga M, Tanioka K, et al. Radical treatment for walled-off necrosis: transmural nasocyst continuous irrigation. Dig Endosc 2019;31(3):307-315

53 Arvanitakis M, Delhaye M, Bali MA, et al. Pancreatic-fluid collections: a randomized controlled trial regarding stent removal after endoscopic transmural drainage. Gastrointest Endosc 2007;65(4):609-619

54 Rana SS, Bhasin DK, Rao C, Sharma R, Gupta R. Consequences of long term indwelling transmural stents in patients with walled off pancreatic necrosis \& disconnected pancreatic duct syndrome. Pancreatology 2013;13(5):486-490

55 Dhir V, Adler DG, Dalal A, Aherrao N, Shah R, Maydeo A. Early removal of biflanged metal stents in the management of pancreatic walled-off necrosis: a prospective study. Endoscopy 2018;50(6):597-605

56 Dhir V, Teoh AY, Bapat M, Bhandari S, Joshi N, Maydeo A. EUSguided pseudocyst drainage: prospective evaluation of early removal of fully covered self-expandable metal stents with pancreatic ductal stenting in selected patients. Gastrointest Endosc 2015;82(4):650-657, quiz 718.e1-718.e5

57 Bang JY, Mel Wilcox C, Arnoletti JP, Varadarajulu S. Importance of disconnected pancreatic duct syndrome in recurrence of pancreatic fluid collections initially drained using lumen-apposing metal stents. Clin Gastroenterol Hepatol 2020;S1542-3565(20):30984-30988

58 Basha J, Lakhtakia S, Nabi Z, et al. Impact of disconnected pancreatic duct on recurrence of fluid collections and new-onset diabetes: do we finally have an answer? Gut 2021;70(3):447-449

59 Varadarajulu S, Wilcox CM. Endoscopic placement of permanent indwelling transmural stents in disconnected pancreatic duct syndrome: does benefit outweigh the risks. ? Gastrointest Endosc 2011;74(6):1408-1412

60 Telford JJ, Farrell JJ, Saltzman JR, et al. Pancreatic stent placement for duct disruption. Gastrointest Endosc 2002;56(1):18-24

61 Varadarajulu S, Noone TC, Tutuian R, Hawes RH, Cotton PB. Predictors of outcome in pancreatic duct disruption managed by endoscopic transpapillary stent placement. Gastrointest Endosc 2005;61(4):568-575 
10 Endoscopic Management of Pancreatic Fluid Collections Shah et al.

62 Trevino JM, Tamhane A, Varadarajulu S. Successful stenting in ductal disruption favorably impacts treatment outcomes in patients undergoing transmural drainage of peripancreatic fluid collections. J Gastroenterol Hepatol 2010;25(3):526-531

63 Yang D, Amin S, Gonzalez S, et al. Transpapillary drainage has no added benefit on treatment outcomes in patients undergoing EUS-guided transmural drainage of pancreatic pseudocysts: a large multicenter study. Gastrointest Endosc 2016;83(4):720-729
64 Amin S, Yang DJ, Lucas AL, Gonzalez S, DiMaio CJ. There is no advantage to transpapillary pancreatic duct stenting for the transmural endoscopic drainage of pancreatic fluid collections: a meta-analysis. Clin Endosc 2017;50(4):388-394

65 Wang L, Elhanafi S, Storm AC, et al. Impact of disconnected pancreatic duct syndrome on endoscopic ultrasound-guided drainage of pancreatic fluid collections. Endoscopy 2020; $\cdots$ : 1213-1489 